\title{
First aid therapy for corrosive chemical eye burns: results of a 30-year longitudinal study with two different decontamination concepts
}

\author{
N. Wiesner ${ }^{1} \cdot$ R. M. Dutescu ${ }^{1} \cdot$ D. Uthoff ${ }^{1} \cdot$ A. Kottek $^{2} \cdot$ M. Reim $^{3} \cdot$ N. Schrage ${ }^{1}$ (D)
}

Received: 26 January 2019 / Revised: 1 April 2019 / Accepted: 2 May 2019 / Published online: 30 May 2019

(C) The Author(s) 2019

\begin{abstract}
Purpose There is currently uncertainty about the most efficacious decontamination solution for corrosive chemical eye burns. This 30-year longitudinal study evaluated the relative efficacy of two different decontamination methods. Passive decontamination consists of rinsing with tap water, $0.9 \%$ normal saline, isotonic buffered phosphate solution, or Ringer's lactate. Active decontamination adds an amphoteric, polyvalent, and chelating component with Previn ${ }^{\circledR}$ (Diphoterine ${ }^{\circledR}$ ) solution (Laboratoire Prevor, Valmondois, France).

Methods A prospective evaluation of patients treated in two specialized eye clinics for eye burns was begun in 1988. Recorded data included exposure circumstances, type of corrosive, different types of first therapy, and clinical treatment and outcome. Patients were treated from clinic admission and up to $24 \mathrm{~h}$ after the corrosive chemical burn with rinsing for 15 min using two different protocols. From 1988 to 2005, sterile 0.9\% normal saline or Ringer's lactate was used. Since 2006, sterile, hypertonic, amphoteric Previn ${ }^{\circledR}$ solution was used. Comparative statistical analysis was done with the Fisher contingency tables and Wilcoxon tests.

Results There were a total of 1495 patients with 2194 chemically burned eyes. In 1988-2005, the annual incidence was 66.1/ year; in 2006-2017, it was 65.5/year. Similar incidences were noted when initial rinsing was with tap water or isotonic buffered phosphate solutions. There was a significantly more severe outcome of corrosive chemical eye burns with any first aid rinsing solutions other than Previn ${ }^{\circledR}$ solution or tap water was used $(p<0.001)$. Previn ${ }^{\circledR}$ solution or tap water rinsing in the pre-hospital setting and secondary rinsing with Previn $®$ solution in the hospital decreased lesion severity in comparison with all other rinsing solutions $(p<0.001)$.

Conclusion The frequency of corrosive chemical eye burns was comparatively high despite tightening of occupational health and safety regulations over the past 30 years. The severity of corrosive chemical eye burns has been dramatically decreased since the introduction of Previn ${ }^{\circledR}$ solution for initial and secondary rinsing. A new protocol for immediate Previn ${ }^{\circledR}$ solution use by the Cologne Fire Brigade and secondary Previn ${ }^{\circledR}$ solution rinsing in hospital has reduced the frequency of severe corrosive chemical eye burns to less than $60 \%$ as compared to the period of 1988-2005 when other rinsing solutions were utilized.
\end{abstract}

Keywords Eye burns · Corrosive chemical eye burns · Decontamination · Water · Electrolyte solutions · Isotonic buffered phosphate $\cdot$ Amphoteric solution

N. Schrage

schragen@kliniken-Koeln.de

1 Department of Ophthalmology Cologne Merheim, Kliniken der Stadt Köln, Ostmerheimer Str. 200, 51109 Cologne, Germany

2 Aachen, Germany

3 Department of Ophthalmology, RWTH Aachen University, Pauwelsstr. 30, D-52057 Aachen, Germany

\section{Introduction}

The optimal first aid measures immediately after corrosive chemical eye burns have long been the subject of discussion. Best clinical practice consensus is that eye rinsing, as soon as possible after a corrosive chemical ocular splash, should be done with a neutral $\mathrm{pH}$ aqueous flushing solution [1]. However, the efficacy of the various solutions frequently utilized has yet to be proven in published prospective studies. Currently, it is common practice to utilize eye rinsing, as soon after the exposure as can be done, to remove as much corrosive chemical as possible and preserving the $\mathrm{pH}$ milieu of the 
anterior chamber. Doing so is assumed to result in better clinical outcomes [2].

Current debate is over which ringing solutions(s) is/are most efficacious in preventing or mitigating potentially serious ocular injuries following a corrosive chemical eye splash. One school of thought endorses eye rinsing with large amounts of tap, distilled, or sterile water. Another prefers eye rinsing with various sterile electrolyte solutions such as $0.9 \%$ normal saline, Ringer's lactate, BSS (balanced salt solution including citrate and buffer), saline solution, isotonic or hypertonic buffered phosphate solution, or isotonic buffered borate solution. A third advocates specialized rinsing fluids such as sterile, water-based, polyvalent, chelating, amphoteric solutions.

The authors have retrospectively studied the issue of a preferable eye rinsing solution by examination of 30 years of medical records in a prospectively collected registry of patients with corrosive chemical eye burns treated in their own institutions.

In recent years, the authors have experimentally investigated three types of irrigation for first aid treatment of corrosive chemical eye burns [3]. Decontamination experiments were performed in rabbit eyes exposed to sodium hydroxide $(\mathrm{NaOH})$ and decontaminated with tap water, $0.9 \%$ normal saline, Ringer's lactate, isotonic buffered phosphate, hyperosmolar solution ("Plum's solution"), and $\mathrm{pH}$ neutral Previn ${ }^{\circledR}$ (Diphoterine ${ }^{\circledR}$ ) solution (Laboratoire Prevor, Valmondois, France). Previn ${ }^{\circledR}$ and Diphoterine ${ }^{\circledR}$ solutions have essentially the same ingredients, with the exception of different preservatives used in Germany (Previn ${ }^{\circledR}$ solution) and the rest of the world (Diphoterine ${ }^{\circledR}$ solution).

The intraocular anterior chamber $\mathrm{pH}$ was measured over 20 min following an experiment with a 30-s $1 \mathrm{M}$ sodium hydroxide eye burn with horn etching followed by rinsing with the various solutions listed above. In these experimental conditions, the $\mathrm{pH}$ peaked at 12.3 at $2.5 \mathrm{~min}$ after the exposure. With tap water rinsing for $15 \mathrm{~min}$, the $\mathrm{pH}$ decreased to 11 . With isotonic solutions rinsing $(0.9 \%$ normal saline, isotonic phosphate buffered solution, Ringer's lactate), the $\mathrm{pH}$ remained high at 12 . Isotonic buffered borate solution rinsing decreased the $\mathrm{pH}$ to 9 . Sterile, hyperosmolar, polyvalent, chelating amphoteric Previn ${ }^{\circledR}$ solution [4] decreased the intraocular $\mathrm{pH}$ to $8-9$ following a $15-\mathrm{min}$ rinsing. The generally accepted physiologically tolerable $\mathrm{pH}$ for the eye is 5-9.

Epithelial regeneration and corneal opacity clearing are essential for the healing of corrosive chemical eye burns. Such healing depends on the burn severity and type of early intervention [5] which can in experimental and clinical settings lead to significantly improved outcomes. Randomized prospective clinical trials are currently lacking. Clinical efficacy of corrosive chemical eye burns rinsing is thus based on a clear experimental and an empirical clinical basis. There are indications based on a systematic review that early irrigation of corrosive chemical eye burns is advantageous in all situations and that utilization of sterile rinsing solutions such as $0.9 \%$ isotonic normal saline, BSS, Ringer's lactate, or Previn ${ }^{\circledR}$ solution resulted in better clinical outcomes.

In a prospective study from the island of Martinique, replacement of isotonic sterile $0.9 \%$ normal saline rinsing with sterile, hypertonic, polyvalent, chelating, amphoteric Diphoterine ${ }^{\circledR}$ solution resulted in a reduction of the severity of ammonium hydroxide eye burns over a 1-year period [6]. However, relatively few patients were evaluated in this study.

Published studies of rinsing or corrosive chemical eye burns generally lack a consistent assessment based on the burn type, type of corrosive chemical involved, and classification of eye burns associated with early rinsing with various solutions. Many studies lack a sufficient number of treated patients. Based on the authors' review and knowledge of ex vivo and experimental animal studies, for ethical reasons, they declined to begin a prospective randomized study as available data showed that results with tap water, $0.9 \%$ normal saline, and hyperosmolar solutions were very different. The only possible prospective randomized clinical study would have been a comparison of hyperosmolar Previn ${ }^{\circledR}$ solution and hyperosmolar Plum's Buffer (Plum's pH neutral ${ }^{\circledR}$ ) solution. As the latter solution has been shown to result in corneal calcification in experimental studies and in certain clinical cases [7, 8], this was considered by the authors to be ethically unacceptable.

Instead, the authors decided to perform an evaluation of clinical outcomes by a retrospective longitudinal study of a prospectively collected existing registry of all cases of corrosive chemical eye burns treated over a 30 -year period in their specialist ophthalmologic institutions by selectively changing rinsing solution protocols.

\section{Materials and methods}

In order to clarify clinical observations of eye burns, the group headed by two of the authors (MR and NS) initiated a prospectively collected registry of all their clinical cases [9-11]. All patients treated with an ICD Code of T26.9 (Buns of eye and conjunctiva) were registered. Data evaluation was performed according to all applicable regulations, which have changed over the past 30 years. Data were under the control of and available to only the authors. All patient identifying data were removed from the original records and identification numbers substituted for data evaluation.

Data recorded in the registry included medical history, clinical emergency files, first aid treatment of all cases of corrosive chemical eye burns, eye burn circumstances, date and time of the splash injury, time of exposure, time to first aid treatment initiation, type of rinsing solution utilized, 
secondary aid rinsing solution utilized, clinical burn severity according to Reim's classification [10], and outcome.

Two protocols were used for initial corrosive chemical eye exposures in the emergency department of the RWTH Aachen Hospital and later (from 2004) in the Cologne Merheim Hospital emergency department or pre-hospital in the ambulance. The eyes were rinsed for 15 min with Previn ${ }^{\circledR}$ solution within the first $24 \mathrm{~h}$ following corrosive chemical exposure. From 1988 to 2005, exposed eyes were rinsed for $15 \mathrm{~min}$ with either sterile $0.9 \%$ normal saline or sterile Ringer's lactate. Starting in 2006, exposed eyes were instead rinsed with sterile, hypertonic, amphoteric Previn ${ }^{\circledR}$ solution.

Data were collected into a Filemaker ${ }^{\circledR}$ database: FileMaker, Inc. 5201 Patrick Henry Drive Santa Clara, CA 95054, with queries for, corrosive chemical type (e.g., acids, alkalis, detergents, solvents, calcareous solids like Portland cement, and unknown materials. Further data criteria were patient age, time to initiation of first aid eye irrigation, type of first aid treatment and location, type of secondary aid and location, visual acuity upon reception, and severity of eye burns for each eye including a detailed eye burn description.

Statistical analysis utilized descriptive statistics for frequency, type, and injury grade (Reim, Roper-Hall) of eye burns. The authors evaluated the different interventions. The group treated from 1988 to 2005 received first and secondary rinsing with normal saline, tap water, or Ringer's lactate. In the group treated from 2006 to 2017, first aid intervention could be with any of those solutions used in first group or Previn ${ }^{\circledR}$ solution; secondary intervention was with Previn ${ }^{\circledR}$ solution.

Parametric and nonparametric statistical analyses were with the Wilcoxon test and Fisher's contingency tables using GraphPad PrismVer. 5.0 software: GraphPad Software 2365 Northside Dr. Suite 560 San Diego, CA 92108, for statistical analysis. Null hypothesis tests were carried out using the Tukey Cramer and chi square analyses for the post-test.

\section{Results}

The registry contained data on a total of 1495 patients with 2194 corrosive chemical substance burned eyes. Patient ages ranged from children $0-5$ years to those $>70$ years of age. The peak incidence occurred in those aged 26-30 years (Table 1). The majority of patients were males with ages ranging from 16 to 50 years. The incidence of such eye burns was 66.1 cases/year from 1988 to 2005, and 65.5 cases/year from 2006 to 2017.

\section{Accident site and first aid treatment}

The accident site was domestic in 404 patients $(27 \%)$ and in the workplace in 919 cases $(61 \%)$. It was uncertain where the
Table 1 Age distribution

\begin{tabular}{ll}
\hline Age (years) & Number of patients \\
\hline $0-5$ & 49 \\
$6-10$ & 57 \\
$11-15$ & 39 \\
$16-20$ & 143 \\
$21-25$ & 178 \\
$26-30$ & 195 \\
$31-35$ & 154 \\
$36-40$ & 169 \\
$41-45$ & 125 \\
$46-50$ & 119 \\
$51-55$ & 79 \\
$56-60$ & 89 \\
$61-65$ & 29 \\
$66-70$ & 24 \\
$>70$ & 26 \\
Uncertain data & 29 \\
Total & 1504 \\
\hline
\end{tabular}

accident occurred in 181 cases (12\%). Time to initial first aid eye rinsing was determined from the patients' medical histories. Type of first aid rinsing that was reported by the patients (Table 2).

Table 2 Type of first aid rinsing solution

\begin{tabular}{|c|c|}
\hline $\begin{array}{l}\text { First aid rinsing } \\
\text { solutions }\end{array}$ & $\begin{array}{l}\text { Number } \\
\text { of } \\
\text { patients }\end{array}$ \\
\hline Buffer solution & 2 \\
\hline $\begin{array}{l}\text { Chibro Cadron } \\
\text { Drops }{ }^{\circledR}\end{array}$ & 1 \\
\hline Coca Cola ${ }^{\circledR}$ & 1 \\
\hline Eye Rinsing & 8 \\
\hline Isogutt® & 15 \\
\hline $0.9 \% \mathrm{NaCl}$ & 60 \\
\hline No rinsing & 14 \\
\hline Oculav NIT® & 1 \\
\hline Ophthalmin ${ }^{\circledR}$ drops & 1 \\
\hline Previn $®$ solution & 70 \\
\hline Red wine & 1 \\
\hline inger's lactate & 56 \\
\hline Sohthal POS N® & 2 \\
\hline Stereofundin ${ }^{\circledR}$ & 3 \\
\hline Uncertain data & 14 \\
\hline Uncertain rinsing & 379 \\
\hline $\begin{array}{l}\text { Unknown rinsing } \\
\text { fluid }\end{array}$ & 250 \\
\hline Water & 639 \\
\hline WERO® & 1 \\
\hline Total & 1504 \\
\hline
\end{tabular}


Table 3 Time to first rinsing after burns

\begin{tabular}{ll}
\hline $\begin{array}{l}\text { Time to first aid } \\
\text { rinsing }\end{array}$ & $\begin{array}{l}\text { Number } \\
\text { of } \\
\text { patients }\end{array}$ \\
\hline $0(0-3 \mathrm{~s})$ & 116 \\
$1(4-10 \mathrm{~s})$ & 169 \\
$2(11-30 \mathrm{~s})$ & 169 \\
$3(31-120 \mathrm{~s})$ & 277 \\
$4(121-360 \mathrm{~s})$ & 60 \\
$5(6$ min to $1 \mathrm{~h})$ & 157 \\
6 (no rinsing) & 193 \\
7 (uncertain & 363 \\
rinsing) & 1504 \\
\hline
\end{tabular}

Patients were divided into groups based on the apparent lapsed time to beginning of first aid eye rinsing: $0-3 \mathrm{~s}(n=$ $100)$; 4-10 s $(n=297) ; 11-30 \mathrm{~s}(n=169) ; 31-120 \mathrm{~s}(n=162)$; $121-360 \mathrm{~s}(n=49) ; 360 \mathrm{~s}$ to $1 \mathrm{~h}(n=160) ;>1 \mathrm{~h}$ or no initial irrigation ( $n=188)$; undetermined time to initial eye irrigation $(n=370)$ (Table 3$)$.

The type of first aid rinsing done by the patient or professional responders was water $(n=639)$; unknown rinsing solution $(n=157)$; no first aid rinsing $(n=187)$; uncertainty about initial first aid rinsing $(n=242)$; Previn ${ }^{\circledR}$ solution $(n=96)$; Ringer's lactate $(n=67)$; Isogutt $\AA$ (isotonic phosphate buffer) $(n=14)$; Sterofundin $®$ (an istotonic saline solution) $(n=3)$; and rinsing done but no recording of rinsing fluid type $(n=23)$.

\section{Secondary rinsing}

Documented secondary rinsing in the ophthalmology clinic was $0.9 \%$ normal saline $(n=68)$; Ringer's lactate $(n=19)$; unknown rinsing solution ( $n=151$ ); Isogutt $®$ (isotonic phosphate buffer) $(n=6)$; water $(n=5)$; Previn $\AA$ solution $(n=$ $185)$; and no secondary rinsing $(n=151)$ (Table 4$)$.

\section{Type of corrosive chemicals involved}

There were 815 corrosive chemical substances identified as being responsible for eye splashes in the total study population: calcareous including cement $(n=187)$; alkalis $(n=178)$; acids $(n=$

Table 4 Secondary rinsing fluid in hospital/clinic

\begin{tabular}{ll}
\hline $\begin{array}{l}\text { Secondary } \\
\text { rinsing fluid }\end{array}$ & $\begin{array}{l}\text { Number } \\
\text { of patients }\end{array}$ \\
\hline $0.9 \% \mathrm{NaCl}$ & 87 \\
No rinsing & 314 \\
Previn® solution & 307 \\
Ringer's lactate & 75 \\
Tap water & 2 \\
Total & 785 \\
\hline
\end{tabular}

167); surfactants $(n=139)$; tear "gas" $(n=117)$; heat and steam $(n=106)$; others were in smaller groups of $<100$.

\section{Location of first aid rinsing}

Of the total, 660 patients had first aid eye rinsing at the accident site, 73 were rinsed by firefighters, 48 by first aid providers in a general hospital, and 114 by an ophthalmologist. Accurate reporting of the location of first aid rinsing was either not reported or data were missing for $>609$ patients.

\section{Time to first aid eye irrigation and lesion severity}

For the entire study group looking at the delay to initiation of first aid irrigation, there was a mixture of grade $0-4$ eye burns (Reim, Roper-Hall). There was a nonstatistically significant trend for eye burns to be more severe in those who received early irrigation, delayed irrigation, or no first aid irrigation. To address a second possibility for increased eye burn severity, the type of first aid irrigation fluid was evaluated: tap water; isotonic phosphate buffer, Ringer's lactate, $0.9 \%$ normal saline, and Previn ${ }^{\circledR}$ solution. The results of this analysis are shown in Table 5 and Fig. 1.

Following first aid treatment with tap water or Previn ${ }^{\circ}$ solution, the severity of corrosive chemical eye burns decreased significantly. The difference between tap water and Previn $\AA$ in first aid was insignificant concerning the overall outcome of severity. Much worse clinical outcomes were found following first aid rinsing with isotonic phosphate buffer, $0.9 \%$ normal saline, and Ringer's lactate. These results were significantly different $p<0.001$ for all substances versus tap water and Previn or the tap water+ Previn $®$ considerations.

Secondary rinsing in the hospital emergency department was also evaluated according to the rinsing fluid utilized (Table 6). All patients evaluated in the ophthalmology clinic from 1988 to 2005 had secondary rinsing with either $0.9 \%$ normal saline or Ringer's lactate for 15 min. From 2006 onwards, secondary rinsing was with Previn ${ }^{\circledR}$ solution for $15 \mathrm{~min}$. Evaluation of the first aid rinsing fluid followed by the secondary rinsing solution revealed that in those patients initially rinsed with tap water and secondarily rinsed with $0.9 \%$ normal saline, the severity remained high. When patients were initially rinsed with any other rinsing fluid and secondarily rinsed with Previn ${ }^{\circledR}$ solution, the injury severity was decreased $p<0.001$ for Previn ${ }^{\circledR}$ (Fig. 2).

Eye burn severity grades (Reim, Roper-Hall) were divided into two groups for analysis: those that can be expected to heal spontaneously (grades 0-2) and those that do not heal spontaneously (grades 3 and 4). This evaluation showed that first aid rinsing with either tap water or Previn $®$ solution resulted in statistically significant better clinical outcomes compared to $0.9 \%$ saline solution $(p<0.03)$ and either Ringer's lactate or isotonic phosphate buffer $(p<0.001)$, and in those cases where data on rinsing solutions were missing $(p<0.001)$. 
Table 5 Initial rinsing medium and severity grade

\begin{tabular}{lll}
\hline Initial rinsing fluid & Grades 0-2 (number of patients) & Grades 3 and 4 (number of patients) \\
\hline Tap water & 818 & 64 \\
Previn® & 134 & 5 \\
Isotonic phosphate buffer & 6 & 13 \\
Ringers lactate & 63 & 35 \\
$0.9 \%$ saline solution & 78 & 19 \\
Missing data & 291 & 79 \\
Totals & 1390 & 315 \\
\hline
\end{tabular}

The effect of initial rinsing and result in severity of eye burns classified following healing (grade 0-2) and nonhealing eye burns (grades 3 and 4) are shown. There is a clear statistical evidence that tap water and Previn ${ }^{\circledR}$ solution decontaminate statistically significantly better than saline solution $(p<0.03)$ Ringer's lactate, phosphate buffer, and missing data $p<0.001$. Saline solution was slightly better in decontamination in this analysis than isotonic electrolytes $(p<0.03)$
Isotonic saline solution was slightly better than isotonic electrolyte solutions in this analysis $(p<0.03)$.

\section{Discussion}

The dataset presented here was obtained from a large, prospectively collected registry of patients with corrosive chemical eye burns during a 30-year period from 1988 to 2017 and reflects various factors. In order to evaluate these data, the specific local study characteristics must be considered. First, changes in the legislative, industrial, and administrative environment occurred during this 30-year study period. The incidence of corrosive chemical eye burns was constant at 66.1 cases/year from 1988 to 2005 , and was 65.5 cases/year from 2006 to 2017.

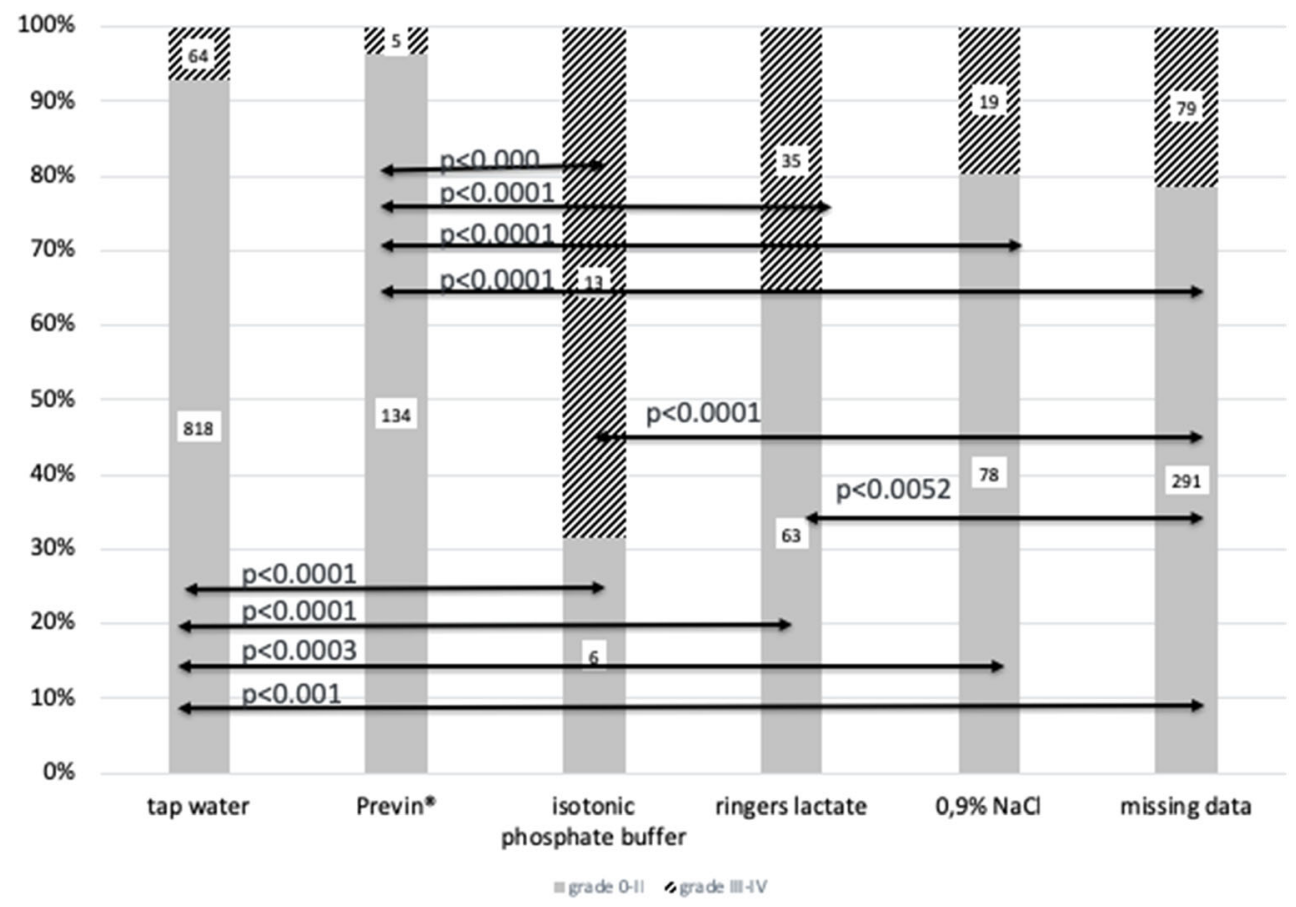

Fig. 1 Table 5 in graphical and statistical analysis. Gray columns represent all grade 0 -II and hatched columns represent all grade II + IV eye burns following Reim's classification. Numbers in columns give the total of eyes classified and treated with the solutions of the columns indicator. There is visible evidence that hatched columns are much smaller for tap water and Previn ${ }^{\circledR}\left(\right.$ Diphoterine $\left.{ }^{\circledR}\right)$ in first aid rinsing as for other rinsing solutions and for missing data. In statistical analysis Graphpad Prism ${ }^{\circledR}$ software, there are highly significant results testing the hypothesis of proportions of grade 0 -II to grade III + IV eye burns in the Fisher contingency tables indicated by $p$ values compared between the columns indicated by arrows with the associated $p$ value above. From these results, we conclude that the first two substances are capable to prevent severe eye burns if used in first aid after corrosives contacts with the eye. The worst effect has been observed for isotonic phosphate buffer even the group is very small the results are statistically significant. Ringers lactate and saline proved to be of no advantage concerning the resulting severity of eye burns 
Table 6 Effect of initial rinsing in combination with secondary rinsing

\begin{tabular}{|c|c|c|c|c|c|}
\hline & Secondary rinsing: & Tap water & $\mathrm{NaCl} 0.9 \%$ & Previn $®$ & "Others" \\
\hline First aid rinsing: & Degree of severity & & & & \\
\hline \multirow[t]{2}{*}{ Tap water } & $0-\mathrm{II}$ & 6 & $65 *$ & $226 *$ & 186 \\
\hline & III and IV & 2 & $18 *$ & $11 *$ & 14 \\
\hline \multirow[t]{2}{*}{$\mathrm{NaCl} 0.9 \%$} & 0 -II & 0 & $6 *$ & $8 *$ & $10 *$ \\
\hline & III and IV & 0 & $4 *$ & $1 *$ & $3 *$ \\
\hline \multirow[t]{2}{*}{ Previn ${ }^{\circledR}$} & 0 -II & 0 & 0 & 12 & 0 \\
\hline & III and IV & 0 & 0 & 3 & 0 \\
\hline \multirow[t]{2}{*}{ Others } & $0-\mathrm{II}$ & 0 & $9 *$ & $41 *$ & $48 *$ \\
\hline & III and IV & 0 & $9 *$ & $1 *$ & $35 *$ \\
\hline
\end{tabular}

"Others": Ringer's lactate isotonic phosphate buffer+Sterofundin+"unspecified rinsing": There is clear evidence that concerning the secondary rinsing, the reduction of severe cases is statistically significant higher in cases using Previn ${ }^{\circledR}$ solution secondary to $0.9 \% \mathrm{NaCl}$, "others". In cases using "others" as initial rinsing, the use of Previn ${ }^{\circledR}$ solution following "others" is significantly better than the use of $0.9 \% \mathrm{NaCl}$ in secondary rinsing. There is no statistical proof that secondary rinsing with Previn ${ }^{\circledR}$ solution is better in cases initially rinsed with tap water compared to "others"
With renewal of the Occupational Health and Safety Act 1996 [12] and the Hazardous Substances Ordinance 1998 [13] which was continuously amended until 2010 , legal precautions of safety legislation have changed. Legislation aims to identify hazardous substances and prevent accidents through improved handling of such substances. There were cycles of innovations with procedural changes, but the annual frequency of corrosive chemical eye burns remained very similar during the 30-year study period.

The change of study sites from Aachen to Cologne in 2004 did not lead to a change in the type and number of patients treated in the ophthalmology clinic. In the region along the Rhine River, 419 chemical manufacturing facilities are located. More than 90,000 workers are employed there [14]. In addition, accidents involving corrosive chemical substance exposures also occur in the construction, cleaning, and food industries.

The current study found differences compared to a large American study of more than 160,000 eye burns which noted more burns in the domestic setting, slightly more men than women so injured, an average age of 32-33 years, and greater numbers of affected children [15]. The overall incidence of gender and age in the study reported here is much more similar to findings in a British study [16]. In the current study, the percentage of total patients younger than 15 years was $<8 \%$. This might be due to the fact that patient access to the authors' specialty clinics tended to be reserved for the most serious and devastating cases. Specific questions were asked in the specialty clinic setting and recorded in the registry. Pediatric eye burns are often less severe and tend to heal under the care of local ophthalmologists. Thus, they were not entered into the registry used for the current study.

In a systematic review of the data in the Aachen-Cologne registry, uncertainties were found. For example, the authors were unable to ascertain how long patients were exposed to the involved corrosive chemical before initial irrigation was commenced. This is illustrated by the fact that while there is clear experimental evidence that very early initiation of rinsing following an exposure results in a lower grade of eye burn severity and improved outcome, in the current clinical study, those patients who received very early irrigation initiation had more serious (grades 3 and 4 ) burns than did those patients for whom irrigation initiation was commenced later. In many accidents, the initial exposure is difficult to determine as to involved corrosive substance type, amount, and the time patients were exposed to the chemical substance before rinsing was commenced. Thus, these factors could only be obtained from the patient's medical history which lacks objectivity in assessment of these parameters in relation to questions asked at the time of the accident.

A further point of uncertainty is the dependence of the severity of the eye lesion on the type of corrosive chemical substance involved, which has not been evaluated in the current study. An in-depth review and analysis of the registry data to determine exposures to which corrosive chemical substances leads to the most severe eye burns and whether passive irrigation with tap water or active decontamination with sterile, polyvalent, chelating, amphoteric solutions is associated with the best clinical outcomes is ongoing and will be the subject of a future publication. It is planned to evaluate this at a severity grade level with corrosive chemical substance analysis and then add these most corrosive agents to the evaluation of irrigation solutions as a second step. Evaluation of the visual outcome was insufficient for analysis yet; thus, we could not include these data.

Only a few systematic references are available to evaluate the clinical efficacy of first aid rinsing. In an approach similar to that of the current study, Merle et al. [6] studied exposures to corrosive ammonium hydroxide $\left(\mathrm{NH}_{4}-\mathrm{OH}\right)$ using an existing protocol of $0.9 \%$ normal saline irrigation and then 
Fig. 2 All cases where initial rinsing with tap water was done we consider in this Fig. 2 the effect of the secondary rinsing in our department with three different fluids. The columns indicate in light gray the grades $0-$ II and in black the grades III and IV following Reim's classification of eye burns. Comparing numbers of healing (grade 0-II) to nonhealing (III and IV) burns by means of the Fisher contingency analysis by Graphpad Prism $®$, the difference of a lower proportion of severe eye burns after secondary rinsing with Previn $®$ (Diphoterine $®)$ is statistically significant $(p<0.001)$

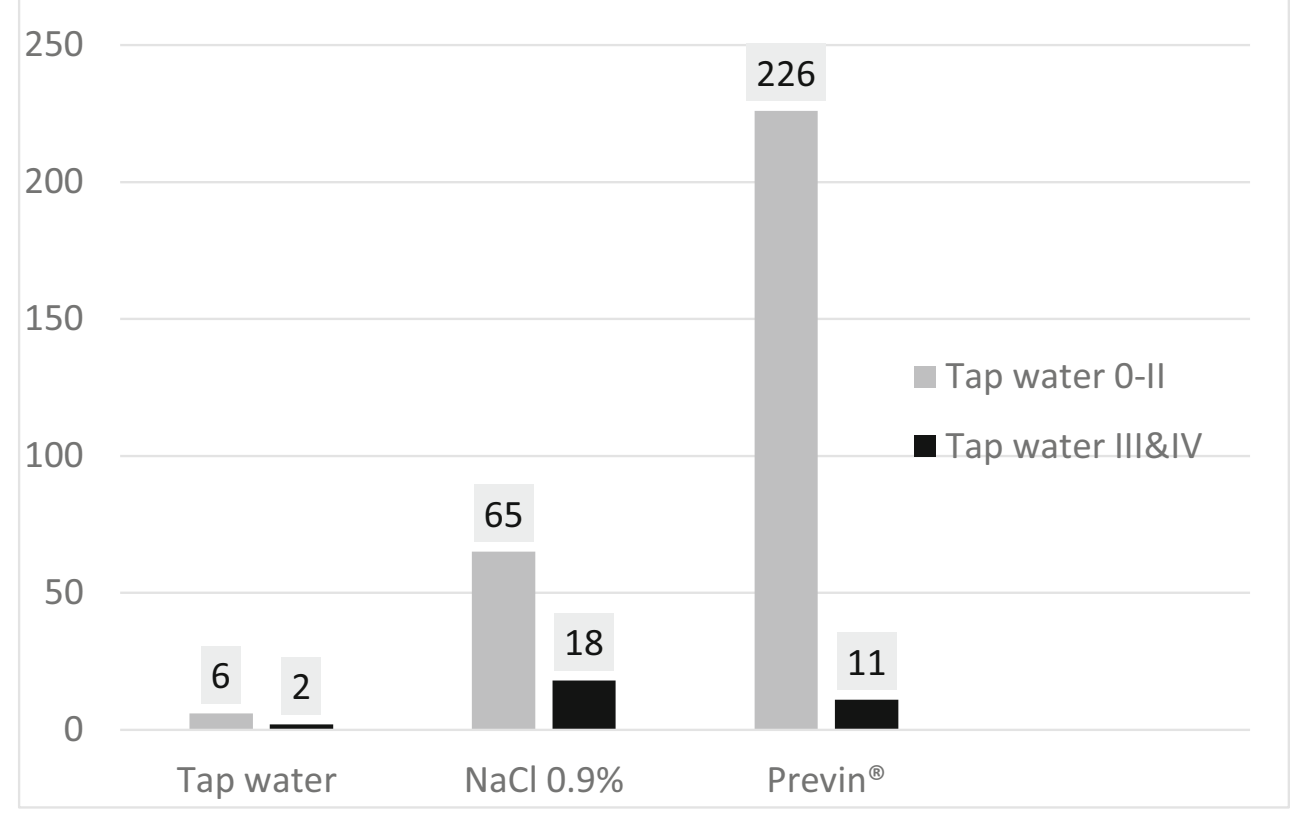

switching to sterile, polyvalent, chelating, amphoteric Diphoterine ${ }^{\circledR}$ solution. Diphoterine ${ }^{\circledR}$ rinsing significantly altered burn severity compared to $0.9 \%$ normal saline rinsing. On the island of Martinique, corrosive chemical eye splashes are commonly deliberate assaults. During the Merle et al. [6] study, some other factors were introduced that might have influenced the noted clinical outcomes, such as an educational program, so that the unambiguous statistically significant improvement with Diphoterine ${ }^{\circledR}$ solution rinsing has been questioned by some.

The second prospective study available is the BSS irrigation study which focused on patient comfort during eye irrigation [17]. This study had no endpoints relevant to clinical outcomes of visual acuity or eye survival. Also, this study disregarded an important factor of severe eye burns which show a complete anterior segment insensitivity to pain due to loss of pain nerves. Therefore, the issue of rinsing comfort is negligible in any question of modulation of the severity of eye burns.

In a systematic review published in 2004, the author's research group showed that first aid rinsing with phosphate buffer is associated with corneal calcifications [18]. Systematic work on in vitro and experimental animal testing results for first aid rinsing of corrosive chemical eye burns have been published by the authors group for years. Evidence of experimental efficacious decontamination has led to several recommendations, such as the current directive of the French Ophthalmological Society (2018) [19] which names Diphoterine $®$ and tap water as key decontamination solutions for corrosive chemical substance eye splashes.
Since Rihawi et al. [5] showed experimentally that immediate rinsing after corrosive chemical substance eye exposure with tap water reduces the eye $\mathrm{pH}$ to $\sim 12$ after 15 min while other rinsing solutions containing electrolytes resulted in an eye $\mathrm{pH}$ of 13 after 2-3 min, the later evolution of the $\mathrm{pH}$ curves was defined by the ability of the rinsing solution to chemically react in regard to decontamination, as was found with borate buffer, Previn ${ }^{\circledR}$ solution, and Diphoterine $₫$ solution. The chemical reactivity of a very concentrated phosphate buffer (Plum $\mathrm{pH}$ neutral ${ }^{\circledR}$ ) showed a more neutral $\mathrm{pH}$ in the anterior chamber. Thus, all pure electrolyte solutions without buffer capacities such as isotonic phosphate buffer could not effectively decontaminate the cornea and the anterior chamber $\mathrm{pH}$ remains high for $>15 \mathrm{~min}$. When the corrosive chemical substance was rinsed with tap water, the anterior chamber $\mathrm{pH}$ was decreased to 11. Decontamination of alkali-exposed eyes with Previn $®$ solution, Diphoterine $®$ solution, or borate buffer reduced the anterior chamber $\mathrm{pH}$ to $8-9$ after $15 \mathrm{~min}$ of rinsing $[2,4,5]$. The generally accepted physiologically tolerable $\mathrm{pH}$ of the eye is $5-9$.

Overall, the most important question is which factors are responsible for true tissue decontamination which supports survival of essential structures such as stem cells, chemical reversal of damage, and protection of surviving structures for subsequent healing. This has been one of the key questions to be addressed in the authors' experimental investigations.

There is evidence that efficacious decontamination is a combination of electrolyte content and chemical activity of rinsing fluids. By corrosive chemical substances penetration into the cornea, corneal diffusion is altered (increased in most 
cases by osmotic and chemical mechanisms). Eye tissue so modified is rarely isotonic, except in rare cases. Thus, hypertonic rinsing solutions are particularly efficacious.

Rinsing solutions with either very high or very low salt concentrations may be considered. With tap water which has a very low salt concentration, immediate dilution occurs which, but leads to obvious tissue swelling. At high salt concentrations, water and the electrolytes it contains are removed from the tissue. Thus, a decisive factor for special hypertonic, amphoteric rinsing solutions is that an active decontamination mechanism is added. This is difficult to achieve with passive dilution which causes a liquid inflow into the tissues. Therefore, the chemical activity of a decontamination solution in reaction with the corrosive chemical substance involved is an additional factor in the acute treatment of eye burns. Simple passive dilution appears less efficacious in this respect [18].

The experimental results described above correspond very well with the clinical data reported here, in which first aid rinsing with either tap water or a hypertonic amphoteric solution resulted in better clinical outcomes. Tap water or Previn ${ }^{\circledR}$ solution as first aid rinsing were associated with less severe eye burns than those seen with isotonic phosphate, isotonic $0.9 \%$ normal saline, and other electrolyte-containing solutions. When evaluating outcomes, comparing the secondary rinsing approach in the clinic after first aid rinsing at the accident site, this becomes more conspicuous, as shown in Table 6. Secondary rinsing with Previn ${ }^{\circledR}$ solution resulted in significantly less severe eye burns as compared to rinsing with all other solutions.

The authors are currently performing a re-analysis of the registry database with emphasis on only the extremely aggressive corrosive chemical substances known to cause severe injury and eliminating from consideration those known to cause very little damage. When this re-analysis is completed, the authors will investigate whether or not the differences found in the current study regarding clinical outcomes with the different first and secondary rinsing solutions can be confirmed.

\section{Conclusions}

Form the current study and the literature reviewed here, the authors conclude that in every emergency department, a triage "Red Flag" should follow the Manchester Triage Criteria [20]. This means that patients with corrosive chemical eye splashes should be decontaminated immediately and efficaciously. As secondary decontamination most often occurs in the hospital, the authors recommend Previn ${ }^{\circledR}$ (Diphoterine ${ }^{\circledR}$ ) solution.

For first aid rinsing at the accident site, in the study reported here, tap water and Previn ${ }^{\circledR}$ solution showed similar results with a slight tendency for less severe burns following rinsing with sterile, hypertonic, polyvalent, chelating, amphoteric
Previn ${ }^{\circledR}$ solution. Such eye burns must be decontaminated as quickly as possible and for $15 \mathrm{~min}$. The corrosive chemical substance should be completely removed from the eye by true decontamination. The initial first aid rinsing must safely remove corrosive chemical substances from the eye tissue surface using a high flow rate. After 2 min of rinsing, however, a drop-by-drop application may be sufficient to achieve decontamination by diffusion.

Acknowledgements The authors like to thank Prof. Alan Hall for careful language review.

Compliance with ethical standards This was a retrospective study of a prospectively collected registry of patients treated for corrosive chemical eye burns in the authors' institutions. All patient-specific identifying information was removed from the registry and replaced with identifying numbers only. No patient-specific identifying information is presented here. For this reason, the authors' institutions do not require approval by an Institutional Review Board or Human Subjects Committee. As the study was performed in Germany, considerations relating to US HIPPA regulations do not apply.

Conflict of interest - Honoraria for speaking at symposia: Novartis, Allergan, Ursapharm

- Employment or consultation: ACTO e.V., P\&G, Prevor Int.

- Support from P\&G, PREVOR, Omnivision, BMBF, AIF research projects

Open Access This article is distributed under the terms of the Creative Commons Attribution 4.0 International License (http:// creativecommons.org/licenses/by/4.0/), which permits unrestricted use, distribution, and reproduction in any medium, provided you give appropriate credit to the original author(s) and the source, provide a link to the Creative Commons license, and indicate if changes were made.

\section{References}

1. Kompa S, Redbrake C, Hilgers C, Wüstemeyer H, Schrage N, Remky A (2005) Effect of different irrigating solutions on aqueous humour $\mathrm{pH}$ changes, intraocular pressure and histological findings after induced alkali burns. Acta Ophthalmol Scand 83(4):467-470

2. Rihawi S, Frentz M, Becker J, Reim M, Schrage NF (2007) The consequences of delayed intervention when treating chemical eye burns. Graefes Arch Clin Exp Ophthalmol 245(10):1507-1513

3. Scott WJ, Schrage N, Dohlman C (2015) Emergency eye rinse for chemical injuries: new considerations. JAMA Ophthalmol 133(3): 245

4. Rihawi S, Frentz M, Schrage NF (2006) Emergency treatment of eye burns: which rinsing solution should we choose? Graefes Arch Clin Exp Ophthalmol 244(7):845-854

5. Rihawi S, Frentz M, Reim M, Schrage NF (2008) Rinsing with isotonic saline solution for eye burns should be avoided. Burns 34(7):1027-1032

6. Merle H, Donnio A, Ayeboua L, Michel F, Thomas F, Ketterle J, Leonard C, Josset P, Gerard M (2005) Alkali ocular burns in Martinique (French West Indies): evaluation of the use of an amphoteric solution as the rinsing product. Burns 31(2):205-211

7. Schrage NF, Frentz M, Reim M (2010) Changing the composition of buffered eye-drops prevents undesired side effects. Br J Ophthalmol 94(11):1519-1522 
8. Schrage NF, Schlossmacher B, Aschenbrenner W, Langefeld S (2001) Phosphate buffer in alkali eye burns as an inducer of experimental corneal calcification. Burns 27(5):459-464

9. Kuckelkorn R, Luft I, Kottek AA, Schrage NF, Makropoulos W, Reim M (1993) Chemical and thermal eye burns in the residential area of RWTH Aachen. Analysis of accidents in 1 year using a new automated documentation of findings. Klin Monatsbl Augenheilkd 203(1):34-42

10. Kuckelkorn R, Makropoulos W, Kottek A, Reim M (1993) Retrospective study of severe alkali burns of the eyes. Klin Monatsbl Augenheilkd 203(6):397-402

11. Kuckelkorn R, Kottek A, Reim M (1994) Intraocular complications after severe chemical burns-incidence and surgical treatment. Klin Monatsbl Augenheilkd 205(2):86-92

12. Abeitsschutzgesetz vom 7. August 1996 (BGBl. I S. 1246), das zuletzt durch Artikel 427 der Verordnung vom 31. August 2015 (BGBl. I S. 1474) geändert worden ist. (2015) https://www. gesetze-im-internet.de/arbschg/BJNR124610996.html. Accessed 10 Oct 2018

13. Gefahrstoffverordnung vom 26. November 2010 (BGB1. I S. 1643, 1644), die zuletzt durch Artikel 148 des Gesetzes vom 29. März 2017 (BGBl. I S. 626) geändert worden ist. (2017) https://www. gesetze-im-internet.de/gefstoffv_2010/BJNR164400010.html. Accessed 10 Oct 2018
14. ChemCologne e.V (2019) Investieren im Rheinland. Die ChemieRegion. http://www.chemcologne.de/chemieland-nrw/zahlen-undfakten.html. Accessed 10 Oct 2018

15. Haring RS, Sheffield ID, Channa R, Canner JK, Schneider EB (2016) Epidemiologic trends of chemical ocular burns in the United States. JAMA Ophthalmol 134(10):1119-1124

16. Blackburn J, Levitan EB, MacLennan PA, Owsley C, McGwin G Jr (2012) The epidemiology of chemical eye injuries. Curr Eye Res 37(9):787-793

17. Herr RD, White GL Jr, Bernhisel K, Mamalis N, Swanson E (1991) Clinical comparison of ocular irrigation fluids following chemical injury. Am J Emerg Med 9(3):228-231

18. Schrage NF, Kompa S, Ballmann B, Reim M, Langefeld S (2005) Relationship of eye burns with calcifications of the cornea? Graefes Arch Clin Exp Ophthalmol 243(8):780-784

19. Bourges JL (ed.) (2018) Urgences en Ophthalmologie. Rapport de la Société Française d'Ophtalmologie (SFO)SFO) | Docteur JeanLouis BOURGES Editeur: Elsevier Masson, pp 254-268

20. Mackway-Jones K, Marsden J, Windle J (eds.). (2011) Ersteinschätzung in der Notaufnahme. Das Manchester-TriageSystem. 3. überarbeitete und ergänzte Auflage

Publisher's note Springer Nature remains neutral with regard to jurisdictional claims in published maps and institutional affiliations. 